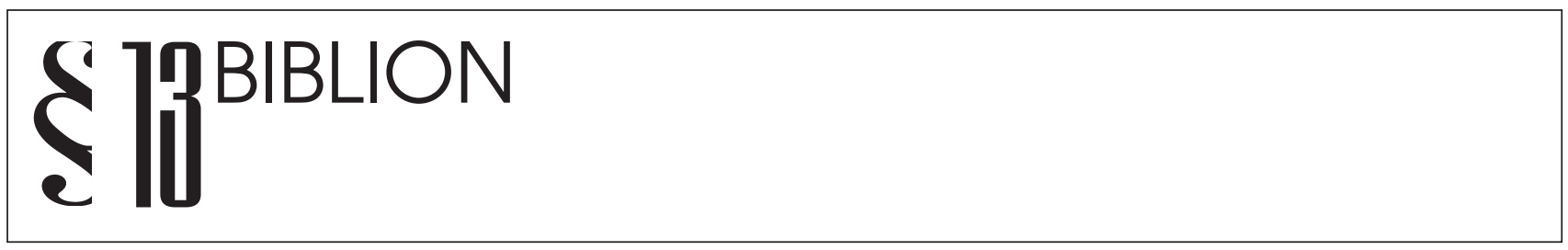

Дубовик О.Л.

\title{
РЕЦЕНЗИЯ: МОДЕЛИ СИСТЕМЫ ПРЕСТУПЛЕНИЙ В СОВРЕМЕННОМ УГОЛОВНОМ ПРАВЕ (Сост. Йордан Айдаров) София: Университетское издательство «Паисий Хилендарский», 2013. - 168 с.
}

\begin{abstract}
Аннотация: В рецензии освещуаются позиции представителей уголовно-правовой науки двух стран - Болгарии и России по вопросу моделирования системы преступлений в уголовном законодательстве современного периода и в историческом аспекте. Эффективные и обоснованные модели систематизации преступлений (ныне их число превынает сотню) призваны обеспечить устойчивость, стабильность и применяемость норм уголовного закона, но до сих пор оптимальной модели наука уголовного права не выработала, а действующее уголовное законодательство России и Болгарии пока что не обеспечивает в должной мере соблюдение всех критериев и условий системности. В работе отмечается общность многих позиций, высказанных болгарскими специилистами по поводу моделирования системы преступлений, с позициями, отраженными в российской уголовно-правовой литературе. Отмечается что рецензируемый сборник является источником информации о современном состоянии и тенденциях развития уголовного права в Болгарии после ее вступления в ЕС, о течениях, существующих в болгарской науке уголовного права. Автор рецензии обращает внимание на то, что в последнее время эта информация стала менее доступной и значительно реже используется при проведении сравнительно-правовых исследований в целом и в уголовном праве в частности. Отмечается высокий уровень и детальность проработки отдельных тем рецензируемых работ, вне зависимости от того идет ли речь об изучении моделей системы преступлений или историко-правововом анализе.
\end{abstract}

Abstract: The review provides references to the positions of criminal law science of Bulgaria and Russia on the issues of modeling the system of crimes in the criminal legislation of the modern period and in the historical aspect. Efficient and substantiated systems of crime systematization (there is over 100 of them right now) are aimed at guaranteeing sustainability, stability and efficient application of norms of criminal law, but still science has not provided for an optimum model, and the current legislations of Bulgaria and Russia still do not satisfy the criteria and conditions for the systemic character. The author notes similarities in many positions of Bulgarian specialists regarding modeling the system of crimes and positions reflected in the Russian criminal law literature. It is noted that the collection is a source of information on the modern situation and tendencies in the criminal law of Bulgaria after it joined the EU, and on the movements in the Bulgarian science of criminal law. The author of the review pays attention to the fact that lately this information became less easily accessible and it is less often used for comparative legal studies in general and studies in criminal law in particular. The author notes high level and detailed character of analysis of many issues whether concerning models of the system of crimes or historical legal analysis.

Ключевые слова: Право, рецензия, преступление, уголовный закон, уголовно-правовой запрет, УК Республики Болгария, категоризация преступлений, уголовно-правовая норма, организованная преступность, системность. Keywords: Law, review, crime, criminal law, criminal law prohibition, the Criminal Code of the Republic of Bulgaria, categorization of crimes, criminal law norm, organized crime, systemic character.

роблематика системности в уголовном праве постоянно привлекает внимание специалистов. В ней обнаруживается множество аспектов: от понимания системы права до бессистем- ности вносимых в УК РФ изменений и дополнений, от подходов к систематике преступлений до системы наказаний (санкций). Недаром еще в 2007 г. по инициативе В.С. Комиссарова II Российский Конгресс 
уголовного права был посвящен обсуждению темы «Системность в уголовном праве» ${ }^{1}$. Множество вопросов было сформулировано, на некоторые из них найдены ответы, некоторые и ныне оживленно дискутируются. В этом ряду несомненный интерес представляет сборник материалов Пятой международной научно-практической конференции, проведенной 12 июня 2012 г. в Софии. В него включены статьи десяти болгарских криминалистов и две статьи российских специалистов в области уголовного права. В предисловии к сборнику, озаглавленному «Модели в уголовном праве» (c.5-7) Ответственный редактор издания, известный специалист в области уголовного права, профессор Й. Айдаров указывает, что рассматриваемые в нем вопросы были сформулированы не случайно: они обусловлены проявляющейся в условиях глобализации хаотичностью нормотворчества в отношении видов преступления. Он подчеркивает, что системность и точность являются отличительными чертами права, в первую очередь уголовного, регулирующего охрану таких важных благ как жизнь и здоровье, окружающая среда, международная безопасность и др. Он указывает, что в настоящее время существует более ста моделей систематизации видов преступлений в различных национальных законодательных актах. Только это свидетельствует о сложности, если не «вечности», исследуемой проблемы. Й. Айдаров подчеркивает - и это чрезвычайно ценное замечание, что систематизация не должны представлять собой только создание каталога, но она должна опираться на принципы моделирования, сообразно защищая права и свободы человека. Нужен и особый критерий такой дифференциации в соответствии с правосознанием. Кроме того, систематизация преступлений должна опираться на ценности, защищаемые уголовным правом.

Статьи, опубликованные в рецензируемом сборнике, можно условно разделить на несколько групп в зависимости от целей исследования и акцентируемых вопросов. В первую группу входят те из них, в которых анализируются общие подходы и делаются оценки модели систематизации преступлений и даже более - системности в уголовном праве (М. Гунева, Т.В. Кленова, В.А. Якушин, Р. Костадинова, С.А. Цанкова-Захариева). Вторую группу образуют статьи, посвященные анализу системных

${ }^{1}$ См.: системность в уголовном праве. Материалы II Российского Конгресса уголовного права. 31 мая - 1 июня 2007 г. / Отв. ред. В.С. Комиссаров. М.: Проспект, 2007. проблем применительно к отдельным категориям преступлений (И. Рапчев, А. Гиргинов, Г. Пенчев).

Общие подходы к анализу моделей систематизации преступлений. Профессор Момина Гунева сформулировала ряд положений о системе и содержании современного Уголовного кодекса Болгарии (с. 8-17). Она отмечает, что вопросы структуры Уголовного кодекса оживленно обсуждаются с тех пор, как был представлен проект нового УК Болгарии. Уголовная политика страны была на протяжении последних 40 лет предметом концентрации законодательных усилий в 1975, 1998, 2008 и 2010 гг. При этом в последних двух случаях, по ее мнению, внимание было в основном сконцентрировано на законодательном регулировании борьбы с определенными видами преступлений, а задача предупреждения преступности почти не затрагивалась. Это очень ценный вывод, который применим и к российскому уголовному законотворчеству. Количество норм Особенной части возросло с 300 до 420 (с. 10). Создается впечатление, что законодатель фиксируется на таких преступлениях как терроризм, трафик, наркотики, организованная преступность, а остальные виды противоправного поведения как бы не существуют. Отметим, что изменения и дополнения УК РФ подтверждают это положение М. Гуневой. Изменения в Особенной части УК РБ выявляют тенденцию подчинения уголовного права определенной политике ЕС, a усиление ответственности за покушение и приготовление демонстрирует тенденцию устрашения, что может привести и к введению уголовной ответственности за намерения (ст. 259 ч.1), что автор статьи совершенно правильно расценивает как недопустимое. Проводимые изменения создают впечатление страха законодателя причем не перед преступностью, а перед общественным мнением и прессой (с.11).

Профессор В.А. Якушина в статье, посвященной анализу факторов, влияющих на системность уголовного законодательства России» (c.18-21) отмечает, что системность российского уголовного законодательства подвергается определенному воздействию со стороны социально-экономических условий и смены общественно-экономического строя в нашей стране. Он указывает на преобладающее ведомственное влияние при внесении законодательных изменений и новых запретов в УК РФ. При этом наибольшему воздействию указанного фактора подвергаются статьи Особенной части об экономических преступлениях, преступлениях против общественной безопасности, здоровья населения и общественной нравственности (в некоторые статьи вносились в течение года 3-4 изменения). С этим 


\section{Право и политика $8(176) \cdot 2014$}

наблюдением, как кажется, согласны многие ученые в России. Еще один значимый фактор, влияющий не только на системность, но и на стабильность уголовного законодательства России, - как считает В.А. Якушин заключается во влиянии лоббистских кругов на депутатов Государственной Думы. Для снижения воздействия ведомственных и лоббистских интересов В.А. Якушин предлагает создать экспертную комиссию из числа наиболее авторитетных ученых. Трудно сказать, насколько эффективна будет реализация данного предложения, но обсудить его, безусловно, стоит еще раз.

В статье профессора Т.В. Кленовой «О специальных нормах в структуре Особенной части Уголовного кодекса» (с.55-65) сформулирована проблема конкуренции уголовно-правовых норм. Эта проблема, как правило, возникает при конкретизации законодательства. Автор отмечает, что: «Универсальным критерием определяющим соотношение общих и специальных уголовно-правовых норм, является объем признаков сообщаемого в норме правила поведения, но не пределы предмета регулирования. Если это запрещающие уголовно-правовые нормы, то они сравниваются как общие и специальные по объему признаков состава преступления» (с. 58). Т.В. Кленова подчеркивает, что не являются конкурирующими составы, в которые включены взаимоисключающие или альтернативные признаки, даже если это составы однородных преступлений. Объем признаков в специальном составе увеличивается за счет признаков, «родственных» общему составу (с. 59). Она анализирует различные позиции, представленные в доктрине российского уголовного права, к которых неодинаково решается вопрос о выборе между абстрактным и казуистическим способами уголовно-правового регулирования. Важный вывод касается того, что основание конкретизации составов преступлений должно определяться в соответствии с основанием криминализации - как существенное изменение общественной опасности деяния и что конкретизация уголовно-правовых норм имеет пределы, которые устанавливаются с учетом социальных целей.

Рамина Костадинова в статье «Систематизация преступлений и уголовная политика Республики Болгария» (с. 131-146) рассматривает проект нового УК РБ, опубликованный Министерством правосудия в начале 2012 г. опираясь на подходы, выработанные в российской и иной литературе к понятию уголовной политики. Она анализирует понятие уголовной политики, а также дает исторический обзор ее формирования через отдельные этапы в развитии уголовного законодательства Болгарии. Учитывая задачу гармонизации с европейским законодательством автор характеризует принятую в 2009 г. Концепцию уголовной политики и разработки нового Уголовного кодекса (с.142-144), выделяя две задачи систематизации преступлений. Это обеспечение целостности, полноты и эффективности защиты общественных отношений; гарантии принципа законности в ходе уголовной репрессии, что важно для Особенной части УК при ее систематизации (с. 145-146).

В статье Сильвии А. Цанковой-Захариевой «Значение общественно опасных последствий в свете систематизации преступлений в Республике Болгария» (c. 147-159) отмечает, что в действующем УК РБ все еще существуют архаичные нормы, а проблема четкого определения в законе общественно опасных последствий является актуальной. Она анализирует составы убийства, террористического действия, широко используя мнения, сформулированные в доктрине уголовного права и выделяет три подхода к общественно-опасным последствиям. Первый инкриминирует как отдельные преступления в системе преступлений «состояния опасности». Второй связан со стадиями преступления, а третий охватывает случаи, когда одно деяние может причинить вред определенным общественным отношениям и поставить в опасность другие общественные отношения (с. 154).

Модели систем отдельных видов преступлений. Они представлены по трем группам преступлений: сексуального характера, организованной преступности и экологических преступлений. Как известно, по разным причинам все они находятся в центре внимания общественности, СМИ и специалистов в области уголовного права и криминологии. В статьях, посвященных этим вопросам, содержится немало новой и полезной информации для российского читателя. Так, в статье д-ра Ивана Ранчева «Сексуальные преступления в системе Особенной части Болгарского Уголовного кодекса» (с.687) анализируются общие предпосылки моделирования и систематизации уголовного закона, исторические аспекты формирования болгарского уголовного права, место сексуальных преступлений в уголовном праве переходного периода и в действующем законодательстве, а также положения проекта нового УК Болгарии. Предлагается уголовную ответственность за посягательства на половую неприкосновенность установить в статьях главы 15, включив в нее пятнадцать составов преступлений (по действующему УК таких составов насчитывается девять).

Профессор Антон Гиргинов посвятил свой доклад сравнительно-правовому исследованию систематизации применительно к уголовно-правовой борьбе с 
организованной преступности в Боснии и Герцеговине и Республике Болгария (с. 88-100). Вначале он рассматривает общие аспекты систематизации преступлений, связанных с организованной преступностью, а затем делает первый шаг - сравнивает уголовное законодательство Боснии и Герцеговины, которые имеют четыре отдельных уголовно-правовых системы - на общегосударственном уровне, в Сербской Республике, в Федерации Босния и Герцеговина, в округе Брочко. Второй шаг заключается в сравнении запретов перечисленных актов с систематикой данного вида преступлений по УК Болгарии. Оригинальна постановка вопроса о систематизации последствий преступлений, связанных с организованной преступностью.

Известный специалист в области уголовно-экологического права, профессор Георги Пенчев, представлен в этом сборнике статьей на тему: «Уголовно-правовая защита окружающей среды по европейскому праву» (c. 101-118). Он анализирует нормы и акты первичного права Европейского Союза, определяющие цели, задачи и пределы охраны окружающей среды (в том числе, осуществляемые средствами уголовного закона, в частности противодействие особо тяжкой преступности с трансграничными последствиями). В статье характеризуются положения Директивы Европейского парламента и Совета от 19 ноября 2008 г. о защите окружающей среды уголовным законом ${ }^{2}$, а также предписания Директиву Европейского парламента и Совета от 7 сентября 2005 г. о загрязнении моря с судов и о применении санкций, включая уголовно-правовые санкции, за нарушения, связанные с загрязнением. Автор считает, что проведенная имплементация положений указанных директив (в том числе изменения, внесенные в ст. 3536 и 353в УК РБ) все же не достаточно полно учитывает рекомендации указанных актов европейского права, поэтому болгарское уголовное законодательство об охране окружающей среды, особенно в части ответственности за нарушение правил обращения с отходами и опасными отходами, нуждается в дальнейшем совершенствовании.

Историко-правовые аспекты систематизации преступлений. Профессор Малина Новкиришка также считает, что проблематика систематизации является в наши дни наиболее актуальной, хотя и очень давней. В своей статье «Система преступлений в Collatio legume Mosaicarum et Romanorum» (c. 22-54) она анализирует

${ }^{2}$ См. о содержании данной Директивы: Экологическая преступность в Европе (Сост. Ф. Комт, Л. Кремер) / Отв. ред. О.Л. Дубовик. М.: Издат. Дом «Городец», 2010. С. 9-14. систематику Моисеева закона и римских законов. Это очень интересная постановка вопроса, а автор статьи продемонстрировала глубокие знания источников права.

В статье Пети Неделевой «Видовые преступления в болгарском обычном праве в период Османского владычества» (c.119-130) характеризуются нормы обычного права, действовавшие после начала Османского нашествия и завоевания Видинского царства (1393 г.) и Тырновского царства (1396 г.). Она анализирует полномочия болгарских общин, роль в самоуправлении православной церкви по ферману Мехмеда II с середины пятнадцатого века и по ферману хана Мустафы III (1773 г.). Она подчеркивает, что болгарское уголовное право до Освобождения отличалось устойчивостью и стабильностью. Знаменательно, что в нем с точки зрения системности выделялись тяжкие и легкие преступления (c.126). П. Неделева характеризует такие преступления как кража, телесные повреждения, повреждение чужого имущества, обиду и клевету и иные, ответственность за которые наступила по нормам обычного права. Она делает вывод, что, несмотря на разрушение болгарской государственности с санкции Османских властей, болгарское обычное уголовное право сохранило свою самобытность и язык (с.130).

Петко Минев анализирует эволюцию института освобождения от уголовной ответственности по статье 78а Уголовного кодекса (c. 160-168) и характеризует проблемы реализации и совершенствования института освобождения от уголовной ответственности с заменой ее административным наказанием, введенного в УК РБ в 1982 г. Он расценивает данную новеллу как законодательный компромисс. Это любопытная позиция, которую стоит обсудить. До этого данный институт формулировался крайне узко: освобождение от уголовной ответственности было возможным за умышленные преступления, наказуемые лишением свободы на срок до одного года, и неумышленные преступления, наказуемые лишением свободы на срок до двух лет. П. Минев иллюстрирует применение ст. 78а УК РБ примерами применения данного института при рассмотрении дел об употреблении наркотических веществ, дорожнотранспортных происшествиях.

Подводя итоги, на мой взгляд, в первую очередь, надо обратить внимание на общность многих позиций, высказанных болгарскими специалистами по поводу моделирования системы преступлений, с позициями, отраженными в российской уголовно-правовой литературе. Далее, рецензируемый сборник является источником информации о современном состоянии и тенденциях развития уголовного права в Болгарии по- 
DOI: $10.7256 / 1811-9018.2014 .8 .12685$

При цитировании этой статьи сноска на доі обязательна

\section{Право и политика $8(176) \cdot 2014$}

сле ее вступления в ЕC, о течениях, существующих в болгарской науке уголовного права. Ведь в последнее время эта информация стала менее доступной и значительно реже используется при проведении сравнительно-правовых исследований в целом и в уголовном праве в частности. Наконец, нельзя не отметить высокий уровень и детальность проработки отдельных тем, будь это общие подходы к изучению моделей системы преступлений или историко-правовой анализ.

\section{Библиография:}

1. Системность в уголовном праве. Материалы II Российского Конгресса уголовного права. 31 мая - 1 июня 2007 г. / Отв. ред. В.С. Комиссаров. М.: Проспект, 2007

2. Акопджанова М.О. Уголовное законодательство России о налоговых преступлениях в советский период // NB: Финансовое право и управление. - 2013. - № 4. - C.30-36. DOI: 10.7256/2306-4234.2013.4.8391. URL: http:/e-notabene.ru/flc/article_8391.html

3. Бакрадзе А.А. Уголовно-правовой анализ проекта постановления Пленума Верховного Суда РФ «О судебной практике по делам о взяточничестве, коммерческом подкупе и иных коррупционных преступлениях» // NB: Вопросы права и политики. - 2013. - № 5. - C.165-180. DOI: 10.7256/23059699.2013.5.793. URL: http://e-notabene.ru/lr/ article_793.html

4. Акопджанова М.О. Основные характеристики и параметры преодоления налоговой преступности // NB: Финансовое право и управление. - 2013. - № 3. - C.25-36. DOI: 10.7256/23064234.2013.3.8396. URL: http://e-notabene.ru/flc/ article_8396.html

5. Чирков Д.К., Литвинов А.А., Антонов-Романовский Г.В., Коимшиди Г.Ф. Сельская преступность в России: современные тенденции и меры противодействия // NB: Национальная безопасность. - 2013. - № 6. -C.155-222. DOI: 10.7256/23060417.2013.6.10530. URL: http://e-notabene.ru/nb/ article_10530.html

6. Костенко Н.И.. Еще раз о проблемах о понятии и составе // Международное право и международные организации / International Law and International Organizations. - 2014. - № 2. - C. 104-107. DOI: 10.7256/2226-6305.2014.2.11360

7. Силаева Н.А. Преступления, посягающие на политическую систему Российской Федерации: криминологическая характеристика (19912011 гг.) // NB: Национальная безопасность. - 2014. - № 2. - C.128-152. DOI: 10.7256/23060417.2014.2.11672. URL: http://e-notabene.ru/nb/ article_11672.html

8. Чирков Д.К., Литвинов А.А., Антонов-Романовский Г.В. Об особенностях преступности мигрантовиностранцев в Российской Федерации // NB: Национальная безопасность. - 2013. - № 3. C.189-200. DOI: 10.7256/2306-0417.2013.3.672. URL: http://e-notabene.ru/nb/article_672.html

9. Кабанов П.А. Политическая преступность в России: криминологический анализ исторического развития // NB: Вопросы права и политики. - 2013. № 1. - C.285-304. DOI: 10.7256/2305-9699.2013.1.474. URL: http://e-notabene.ru/lr/article_474.html

10. Антонова Е.Ю. Уголовная ответственность корпоративного (коллективного) субъекта за коррупционные преступления // NB: Вопросы права и политики. - 2013. - № 3. - C.192-220. DOI: 10.7256/2305-9699.2013.3.568. URL: http://e-notabene. ru/lr/article_568.htm

11. Демидова Л.Н. Системно-функциональный подход и закон о золотой пропорции в уголовном праве // NB: Вопросы права и политики. -2013. - 7. -C. 177 - 192. DOI: 10.7256/2305-9699.2013.7.8802. URL: http://www.e-notabene.ru/lr/article_8802.html

12. Долгих И.П., Шебанов Д.В. Об оптимизации понятия «хищение» в российском законодательстве // NB: Вопросы права и политики. - 2014. - 5. - C. 23 - 37. DOI: 10.7256/23059699.2014.5.11933. URL: http://www.e-notabene. ru/lr/article_11933.html

\section{References (transliteration):}

1. Akopdzhanova M.O. Ugolovnoe zakonodatel'stvo Rossii o nalogovykh prestupleniyakh v sovetskii period // NB: Finansovoe pravo i upravlenie. - 2013. - № 4. S.30-36. DOI: 10.7256/2306-4234.2013.4.8391. URL: http://e-notabene.ru/flc/article_8391.html

2. Bakradze A.A. Ugolovno-pravovoi analiz proekta postanovleniya Plenuma Verkhovnogo Suda RF «O sudebnoi praktike po delam o vzyatochnichestve, kommercheskom podkupe i inykh korruptsionnykh prestupleniyakh»// NB: Voprosy prava i politiki. - 2013. - № 5. - S.165-180. DOI: 10.7256/23059699.2013.5.793. URL: http://e-notabene.ru/lr/ article_793.html 
DOI: $10.7256 / 1811-9018.2014 .8 .12685$

При цитировании этой статьи сноска на dоі обязательна

Biblion

3. Akopdzhanova M.O. Osnovnye kharakteristiki i parametry preodoleniya nalogovoi prestupnosti // NB: Finansovoe pravo i upravlenie. - 2013. - № 3. - S.25-36. DOI: 10.7256/2306-4234.2013.3.8396. URL: http://enotabene.ru/flc/article_8396.html

4. Chirkov D.K., Litvinov A.A., Antonov-Romanovskii G.V., Koimshidi G.F. Sel'skaya prestupnost' v Rossii: sovremennye tendentsii i mery protivodeistviya // NB: Natsional'naya bezopasnost'. - 2013. - № 6. - S.155222. DOI: 10.7256/2306-0417.2013.6.10530. URL: http://e-notabene.ru/nb/article_10530.html

5. Kostenko N.I.. Eshche raz o problemakh o ponyatii i sostave // Mezhdunarodnoe pravo i mezhdunarodnye organizatsii / International Law and International Organizations. - 2014. - № 2. - S. 104-107. DOI: 10.7256/2226-6305.2014.2.11360

6. Silaeva N.A. Prestupleniya, posyagayushchie na politicheskuyu sistemu Rossiiskoi Federatsii: kriminologicheskaya kharakteristika (1991-2011 gg.) // NB: Natsional'naya bezopasnost'. - 2014. - № 2. - S.128152. DOI: 10.7256/2306-0417.2014.2.11672. URL: http://e-notabene.ru/nb/article_11672.html

7. Chirkov D.K., Litvinov A.A., Antonov-Romanovskii G.V. Ob osobennostyakh prestupnosti migrantov-in- ostrantsev v Rossiiskoi Federatsii // NB: Natsional'naya bezopasnost'. - 2013. - № 3. - S.189-200. DOI: 10.7256/2306-0417.2013.3.672. URL: http://e-notabene. $\mathrm{ru} / \mathrm{nb} /$ article_672.html

8. Kabanov P.A. Politicheskaya prestupnost' v Rossii: kriminologicheskii analiz istoricheskogo razvitiya // NB: Voprosy prava i politiki. - 2013. - № 1. - S.285304. DOI: $10.7256 / 2305-9699.2013 .1 .474$. URL: http://e-notabene.ru/lr/article $474 . h t m l$

9. Antonova E.Yu. Ugolovnaya otvetstvennost' korporativnogo (kollektivnogo) sub"ekta za korruptsionnye prestupleniya // NB: Voprosy prava i politiki. - 2013. № 3. - S.192-220. DOI: 10.7256/2305-9699.2013.3.568. URL: http://e-notabene.ru/lr/article_568.htm

10. Demidova L.N. Sistemno-funktsional'nyi podkhod i zakon o zolotoi proportsii v ugolovnom prave // NB: Voprosy prava i politiki. - 2013. - 7. - C. 177 - 192. DOI: 10.7256/2305-9699.2013.7.8802. URL: http:// www.e-notabene.ru/lr/article $8802 . h t m l$

11. Dolgikh I.P., Shebanov D.V. Ob optimizatsii ponyatiya "khishchenie" v rossiiskom zakonodatel'stve // NB: Voprosy prava i politiki. - 2014. - 5. - C. 23 - 37. DOI: 10.7256/2305-9699.2014.5.11933. URL: http://www.enotabene.ru/lr/article_11933.html 